\title{
Carbon, Capture and Storage form Fossil Fuel and Biomass - Uses, Transportation, Cost and Potential Role in Stabilizing the Atmosphere
}

\author{
Akigwe, Ifeanyi M. \\ Enekwechi, K.E \\ Ejikeme, Ifeanyi \\ School of Engineering Technology, Federal Polytechnic, \\ Oko-Anambra State, Nigeria
}

\section{Doi:10.5901/ajis.2013.v2n13p9}

\section{Abstract}

The capture and storage of $\mathrm{CO} 2$ from combustion of fossil fuels is gaining attraction as means to deal with climatic change. Co2 emissions from biomass convention processes can also be captured. If that is done, biomass energy with Co2, Capture and storage (BECS) would become a technology that removes Co2 from the atmosphere and at the same the same time deliver Co2 neutral energy carries (heat, electricity or hydrogen) to society. Here we present uses, transportation, cost and potential role of Co2 capture in stabilizing the atmosphere.

Keywords: Carbon $\left(\mathrm{CO}_{2}\right)$ emission, climatic change, fossil fuel, biomass energy, carbon dioxide capture and storage (CCS)

\section{Introduction}

Carbon Capture and Storage (CCS) is a process where $\mathrm{CO}_{2}$ emitted from large stationary emission sources such as fossil fuel power plants or oil refineries, is captured and stored geologically in the underground.

Capturing $\mathrm{Co}_{2}$ : means separating it from the other components of the exhaust from a particular emission source. The exhaust may contain anything from three to almost 100percent $\mathrm{CO}_{2}$, depending on the nature of the source. For instance, the exhaust from a typical coal power plant contains 12 to 15 percent $\mathrm{CO}_{2}$. the rest is mostly nitrogen and some other gases and particles.

Storing $\mathrm{CO}_{2}$, also known as $\mathrm{CO}_{2}$ sequestration involves compressing the $\mathrm{CO}_{2}$ at high pressure, making $\mathrm{CO}_{2}$ become liquid and then transporting it by pipeline (or possibly ship of the storage site is far away) to a suitable location where it can be stored permanently. Unlike natural gas, $\mathrm{CO}_{2}$ is not a flammable gas, so $\mathrm{CO}_{2}$ transport is safer.

\subsection{How is $\mathrm{CO}_{2}$ Captured?}

The $\mathrm{CO}_{2}$ capture technologies are new to the power industry, they have been deployed for the past sixty (60) years by oil, gas and chemical industries. They are an integral component of natural gas processing and of many coal gasification processes used for the production of synthesis gas, chemicals and liquid fuels. There are three main $\mathrm{CO}_{2}$ capture process for power generation.

i. Post-combustion

ii. post-combustion

iii. oxyfuel combustion 


\subsubsection{Post-combustion:}

Capture involves separating the $\mathrm{CO}_{2}$ from other exhaust gases after combustion of the fossil fuel. Post-Combustion Capture systems are similar to those that already remove pollutants such as particles, sulphur dioxides and nitrogen oxides from many power plants. The most commonly used process for post-combustion $\mathrm{CO}_{2}$ capture is made possible through special chemicals called amines. $\mathrm{A} \mathrm{CO}_{2}$ rich gas stream, such as power plants fuel gas, is "bubbled" through an amine solution. The $\mathrm{CO}_{2}$ bonds with the amines as it passes through the solution while other gas continue through the fuel. The $\mathrm{CO}_{2}$ in the resulting $\mathrm{CO}_{2}$ saturated amine solution is then removed from the amine "Captured" and is ready for carbon storage. The amines themselves can be recycle and re-used. Whilst post-combustion $\mathrm{CO}_{2}$ capture is technically available for coal-based power plant. It has not yet been used commercially for large-scale $\mathrm{CO}_{2}$ removal.

\subsubsection{Pre-Combustion:}

Capture involves separating $\mathrm{CO}_{2}$ before the fuel is burnt. Solid or liquid fuels such as Coal, biomass or petroleum reaction at very high temperature with a controlled amount of oxygen. Gasification produces two gases, hydrogen and carbon monoxide (CO). The $\mathrm{CO}_{2}$ is converted to $\mathrm{CO}_{2}$ and removed, leaving pure hydrogen to burnt to produce electricity or used for another purpose. The $\mathrm{CO}_{2}$ is then compressed into a supercritical fluid for transport and geological storage. The hydrogen can be used to generate power in an advance gas turbine and steam or in fuel cells or a combination of both.

\subsubsection{Oxy fuel:}

Combustion (also called oxy firing) involves the combustion of Coal in pure Oxygen, rather than air to fuel a conventional steam generator. By avoiding the introduction of nitrogen into the combustion chamber, the amount of $\mathrm{CO}_{2}$ in the power station exhaust stream is greatly concentrated, making it easier to capture and compress. Oxy fuel combustion with $\mathrm{CO}_{2}$ storage is currently at the demonstration stage.

\subsubsection{List of international research projects}

- Weyburn and great plains synfuels plant

- Sleipner field in the North Sea,coast of Norway

- The in salah gas plant Algeria

- $\quad$ Mit carbon carbon capture and sequestaration technologies program U.S.A

- Uk Ccs reduction research projects

- Cato 2, the Netherlands

- Solver red programme Germany

Carbon capture and storage from fossil fuels is by many seen as a key technological option to reduce $\mathrm{CO}_{2}$ emissions (see e.g. Parson and Keith, 1998; World Energy Assessment, 2001; Williams, 2001). But it should be noted that the carbon releases from biomass conversion might also be captured and stored (Ishitani and Johansson (1996); Ekstrom et al. (1997); Williams (1998); Keith (2001); Azar et al. (2001); Mollersten and Yan (2001); Obersteiner et al.(2001); Keith and Rhodes (2002). If so, the biomass energy system would deliver $\mathrm{CO}_{2}$ neutral energy carriers such as heat, electricity or hydrogen at the same time as it removes $\mathrm{CO}_{2}$ from the atmosphere. We refer to this concept as Biomass Energy with Carbon Capture and Storage (BECS). If widely applied, the global energy system as a whole could become an instrument to remove $\mathrm{CO}_{2}$ emission from the atmosphere on a continuous basis (as long as storage capacity is available). There are other ways of removing $\mathrm{CO}_{2}$ from the atmosphere, e.g., through afforestation or direct capture from the air, 
but we have not included these options in this study.

In 1995, a total of 6.5 Billion tons of Carbon was released to the atmosphere as $\mathrm{CO}_{2}$. The current concentration of $\mathrm{CO}_{2}$ in the atmosphere is about 360 per million (or 0.36 percent). This is 20percent higher than the level a centry ago, and it is projected to increase to over 700 parts per million (ppm) by the year2010.

\subsection{Innovations/Inventions that will Reduce Energy Requirements.}

\subsubsection{Transportation:}

A technology for $\mathrm{CO}_{2}$ transportation and its environmental safety are well stabilized. $\mathrm{CO}_{2}$ is largely inert in nature and easily handled and is already transported in high pressure pipelines. In the USA, $\mathrm{CO}_{2}$ is already transported by pipeline for use in enhanced oil recovery (EOR) and Food industry. The means of transport depends on the quality of $\mathrm{CO}_{2}$ to be transported, the terrain and the distance between the capture plant and storage site. In general, pipelines are used for large volumes over shorter distance. In some situations or locations, transport of $\mathrm{CO}_{2}$ by ship may be more economical, particularly when the $\mathrm{CO}_{2}$ has to be moved over large distance or overseas.

\subsubsection{Geological Storage}

Geological features being considered for $\mathrm{CO}_{2}$ storage fall into categories;

- $\quad$ Deep saline formations

- Depleted oil and gas fields

- Unmineable coal seams.

As $\mathrm{CO}_{2}$ is pumped deep underground, it is compressed by the higher pressures and becomes essentially a liquid. There are number of different types of geological trapping mechanism (depending on the physical and chemical characteristics of the rocks and fluid) which can be utilized for $\mathrm{CO}_{2}$ storage.

\subsubsection{Geological Trapping Mechanism}

Structure storage: When the $\mathrm{CO}_{2}$ is pumped underground, it is initially more buoyant than water and will rise up through the porous rocks until it reaches the top of the formation where it can become trapped by an impermeable layer of Cap-rocks, such as saline. The wells that were drilled to place the $\mathrm{CO}_{2}$ in storage that can be scaled with plugs made of steel and cement.

\subsubsection{Residual Storage:}

Reservoir rocks act like a tight, rigid sponge. Air in a sponge is residually trapped and the sponge usually has to be squeezed several times to replace the air with water. When liquid $\mathrm{Co}_{2}$ is pumped into a rock formation, much of it becomes stuck without the pore spaces of the rock and does not move.

\subsubsection{Dissolution Storage:}

$\mathrm{CO}_{2}$ dissolves in salty water, just like sugar dissolves in tea. The water with $\mathrm{CO}_{2}$ dissolved in it is even heavier than the water around it (without $\mathrm{CO}_{2}$ ) and so sinks to the bottom of the rock formation. 


\subsubsection{Mineral Storage:}

$\mathrm{CO}_{2}$ dissolved in salt water is weakly acidic and can react with the minerals in the surrounding rocks, formatting new minerals, as coating on the rock (much like shellfish use calcium and carbon from seawater to form their shells). This process can be rapid or very slow

\subsubsection{Deep Saline formations:}

Are underground formations of permeable reservoir rock, such as sandstones, that are saturated with very salty water. (Which would never be used as drinking water) and covered by a layer of impermeable cap rock (e.g shale or clay) which acts as a seal. In case of gas and oil field, it was this cap rock that trapped the oil and gas underground for millions of years. $\mathrm{CO}_{2}$ injected into the Cap rock and the ground water flow and in time, dissolves into the saline water formations is expected to take place at depths below $800 \mathrm{~m}$. saline aquifers have the largest storage potential globally but are the least well-explored and researched of the geological options. However, a number of storage are now using saline formations and have proven their viability and potential.

\subsubsection{Depleted oil and gas fields:}

Are well explored and geologically well-define and have proven ability to store hydrocarbons over geological time spans of millions of years. $\mathrm{CO}_{2}$ is already widely used in the oil industry for enhanced oil Recovery (EOR) from mature oil filed it can mix with the crude oil causing it to swell and thereby reducing its viscosity, helping to maintain or increase the pressure in the reservoir. The combination of these processes allows more of the crude oil flow to the production wells.

\subsubsection{Coal Seam:}

Storage involves another form of trapping in which the injected $\mathrm{CO}_{2}$ is adsorbed onto (accumulates on) the surface of the in situ coal in preference to other gases (such as methane) which are displayed. The effectiveness of the technique depends on the permeability of the coal seam. It is generally accepted that coal seam storage is most likely to be feasible when under taken in conjunction with enhanced coal bed methane recovery (ECBM) in which the commercial production of seam methane is assisted by the displacement effect of the $\mathrm{CO}_{2}$

\subsubsection{Mapping and monitoring:}

Storage projects are carefully tracked through measurement, monitoring and verification (MM\&V) procedures both during and after the period when the $\mathrm{CO}_{2}$ is being injected. These procedures address the effectiveness and safety of storage activities and the behaviour of the injected $\mathrm{CO}_{2}$ underground. $M M \& C$ are used to measure the amount of $\mathrm{CO}_{2}$ stored at a specific geological site, to ensure the $\mathrm{CO}_{2}$ is behaving as expected. The techniques used for MM\&V are largely new applications of existing technologies. These technologies now monitor oil and gas field and waste storage sites. They measure injection rates and pressures, surface distribution of $\mathrm{CO}_{2}$ injection well and local environmental impacts.

The IPCC found the risk of leaking from geological storage was very likely to be less than $1 \%$ over 100 years, and likely to be less than $1 \%$ over 1000 yrs.

\subsubsection{Flue Gas:}

This is the gas existing in the atmosphere via a flue, which is a pipe or channel for conveying exhaust gases from a fireplace, oven furnace, boiler or steam generator. 


\subsubsection{Sequestration:}

Carbon sequestration is the capture of carbon dioxide $\left(\mathrm{CO}_{2}\right)$ from flue gases, such as on power plant station before stored in underground reservoirs.

\section{Emerging Potentials/Uses for $\mathrm{Co}_{2}$}

\subsection{Enhanced Oil recovery (EOR):}

$\mathrm{CO}_{2}$ is injected into depleted oil fields. The $\mathrm{CO}_{2}$ acts as a solvent that reduces the viscosity of the oil, enabling it to flow to the production well. Once production is complete, $\mathrm{CO}_{2}$ can potentially be permanently stored in the reservoir.

\subsection{Urea Yield Boosting:}

Most notable urea production, which globally produced and then consumed an estimated $113 \mathrm{mt}$ pa of $\mathrm{CO}_{2}$. when natural gas is used as the feeds lock for urea production, surplus ammonia is usually produced. A number of projects have been implemented to capture $\mathrm{CO}_{2}$ from ammonia reformer flue gas for injection into the urea production process. Captured $\mathrm{CO}_{2}$ can be reacted with surplus ammonia to form urea. Urea is an example of solid nitrogen fertilizers

\subsection{Oil and gas industry applications:}

$\mathrm{CO}_{2}$ is used as a fluid for the stimulation/ fracturing of oil and gas wells. It is typically trucked to site and injected as liquid carrying propping agents (sand and other materials which prop open the pores of the rock to prevent closure after stimulation).

\subsection{Beverage Carbonation:}

Carbonation of beverages with high-purity $\mathrm{CO}_{2}$

\subsection{Wine making:}

$\mathrm{CO}_{2}$ is used as a seal gas to prevent oxidation of the wine during maturation. $\mathrm{CO}_{2}$ is also produce during the fermentation process, and it is already captured on-site for reuse for its inert gas properties.

\subsection{Food Process preservation and packaging:}

$\mathrm{CO}_{2}$ is used for various applications in the food industry, including cooling while grinding powers such as spices and an insert atmosphere packing (MAP) with products such as cheese, poultry, snacks, produce and red meat, or in controlled atmosphere to prevent food spoilage in packaging application. $\mathrm{CO}_{2}$ is modified atmosphere packaging (MAP) with products such as cheese, poultry, snacks, produce and red meat, or in controlled atmosphere packaging (CAP), where food products are products are packaged in an atmosphere designed to extend shelf-life carbon dioxide is commonly used in MAP and CAP because of its ability to inhibit growth of bacteria that cause spoilage.

\subsection{Coffee decaffeination:}

Superficial $\mathrm{CO}_{2}$ is used as the solvent for decaffeinating coffee. It is preferred due to its inert and 
non-toxic properties.

\subsection{Pharmaceutical processes:}

Use of $\mathrm{CO}_{2}$ in the pharmaceutical industry may overlap with other use identified, as it typically includes inserting, chemical synthesis and supercritical fluid extraction.

\subsection{Horticulture:}

$\mathrm{CO}_{2}$ is provided to green house to maintain option $\mathrm{CO}_{2}$ concentration and maximize plant growth rate. Sources include on-site cogeneration schemes as well as off-site industrial sources connected via pipeline networks.

\subsection{Pulp and paper processing:}

$\mathrm{CO}_{2}$ is used to reduce $\mathrm{pH}$ during pulp wasting operations.

\subsection{Water treatment:}

$\mathrm{CO}_{2}$ is used for re-mineralization of water following reverse osmosis and $\mathrm{pH}$ control (reduction).

\subsection{Inserting:}

$\mathrm{CO}_{2}$ is used in a wide range of applications where the physical properties of an inert gas are desirable. This includes applications covered under other use categories such as welding shielding gas and gas used in food packaging and in wine production.

\subsection{Steel Manufacture:}

$\mathrm{CO}_{2}$ is used in a minority of basic oxygen furnace as a bottom stirring agent. It is also used for dust suppression. Also in blast furnace, scraps are melted and reshaped, irons for molding machine parts, nails, etc and in other foundry projects.

\subsection{Metal working:}

Used for varied purposes, including chilling parts for shrink fitting, and hardening of sand cores and moulds.

\subsection{Supercritical $\mathrm{CO}_{2}$ as a solvent:}

$\mathrm{CO}_{2}$ is useful for high-pressure extraction and as a solvent to isolate targeted compounds, such as fragrances and favour Because of its low critical temperature and moderate pressure requirement, natural substances can be treated particularly gently. It is gaining favour as a solvent in the dry cleaning industry for this reason in niche applications, predominantly as a cleaning fluid.

\subsection{Pneumatics:}

Pneumatic applications for $\mathrm{CO}_{2}$ include use as a portable power source for pneumatic hand tools and equipment, as well as a power source for pain ball guns and other recreational equipment. 


\subsection{Welding:}

Used as a shrouding gas to prevent oxidation of the weld metal.

\subsection{Refrigerant Gas:}

$\mathrm{CO}_{2}$ is used as the working fluid in refrigeration plant, particularly for large industrial air conditioning and refrigeration systems. It replaces more toxic refrigerant gases that also have much greater global warming potential.

\subsection{Fire Suppression Technology:}

When applied to a fire, $\mathrm{CO}_{2}$ provides a heavy blanket of gas that reduces the oxygen level to a point where combustion cannot occur. $\mathrm{CO}_{2}$ is used in fire extinguishers, as well as in industrial fire systems.

\subsection{Enhanced Coal Bed methane Recovery (ECBM):}

In $\mathrm{CO}_{2} \mathrm{ECBM}, \mathrm{CO}_{2}$ is injected into the coal, displacing and releasing adsorbed methane, which can be recovered at the surface

\subsection{Enhanced geothermal system (EGS)-and Power Generation:}

These are two ways in which superficial $\mathrm{CO}_{2}$ may be utilized in EGS geothermal power station/germination; firstly, it may be used as the circulating heat exchange fluid. The benefit here is that the significant density difference between the coal $\mathrm{CO}_{2}$ flowing down the injection well(s) and hot $\mathrm{CO}_{2}$ flowing up the production well (s) would eliminate the need for a circulation pump. Secondly, this concept could be extended, and the circulation $\mathrm{CO}_{2}$ could also be used directed as the working fluid in a super critical $\mathrm{Co}_{2}$ power. Supercritical $\mathrm{Co}_{2}$ power cycles need not be limited to geothermal power plants, as the benefits of high efficiency and compact turbo machinery are not heat source-specific. The nuclear power industry is particularly interested in supercritical $\mathrm{CO}_{2}$ power cycle for this reason.

\subsection{Polymer Processing:}

One example of $\mathrm{CO}_{2}$ as a feed stock polymer processing involves the transformation of carbon dioxide into polycarbonates using proprietary zinc base catalyst system.

\subsection{Chemical Synthesis:}

(Excludes polymers and liquid fuels/hydrocarbons). Carbon and oxygen are both key elements in organic chemistry. Consequently, there are a wide range of chemicals that can at least theoretically utilize $\mathrm{CO}_{2}$ as a feedstock for production, including organic acids, alcohols, esters and sugars. The partiality of $\mathrm{CO}_{2}$ as a feedstock will vary significantly based on the current production routes. The dominant potential demand based $n$ current markets, could come from acetic acid, which has a current global market of LMT Pa. Acetic acid can be produced by direct catalysis of $\mathrm{Co}_{2}$ and methane

\subsection{Algal bio-fixation:}

The productive of algal cultivation systems can be increased significantly (up to a saturation point) 
by the injection/addition of $\mathrm{CO}_{2}$ to the growth medium/solution.

\subsection{Mineralization:}

(Calcium carbonate and magnesium carbonate): Mildly (concentrated Co2 (eg. Power station flue gas) is contacted with mineral -loaded alkaline brine. The $\mathrm{CO}_{2}$ present in the gas precipitates out as mineral carbonate (limestone/dolomite equivalent precipitates). The resulting product can be further processed to form an aggregate equivalent product for the construction industry, and can also potentially displace a small portion of Portland cementing concrete.

\subsection{King soda (sodium Carbonate):}

This is a variant of mineralization wherein $\mathrm{CO}_{2}$ is contacted with sodium rich brine, resulting in the formation of sodium, bi-carbonate $\left(\mathrm{NaHCO}_{3}\right)$.

\subsection{Co2 concrete curing:}

This technology is focused on pre case concrete production facilities, where the waste $\mathrm{CO}_{2}$ form in site flue gas permanently stored as un-reactive limestone within the concrete. This also limits the need for heats and steam in the curing process. The result is a reduction in emission of $\mathrm{CO}_{2}$ equivalent, up to $12 \mathrm{~kg}$ of ton ( $286 \mathrm{ibs} \mathrm{Co}_{2}$ per Us ton) of per case concrete.

\subsection{Bauxite residue treatment (red mud):}

The extraction of aunina form bauxite ore result in a highly alkaline bauxite residue slurry known as" red" Mud" concentrated $\mathrm{CO}_{2}$ can be injected into the red mud slurry to partially neutralize the product, improve its manageability, reducing its disposal costs and limiting its potential environmental impact .In the neutralization process, the $\mathrm{CO}_{2}$ is converted to mineral form (typically carbonates). The resulting product remains slightly alkaline, and has potential as a soil amendment for acidic soils.

\subsection{9 liquid fuels (Renewable method and formic acid):}

Electrolysis of water produces $\mathrm{H}_{2}$. The $\mathrm{H}_{2}$ is combine with captured $\mathrm{CO}_{2}$, compressed and reacted over a catalyst at moderate temperature and pressure $5 \mathrm{mpa}-2250 \mathrm{c}$ to produce methanol and water. Electro-reduction of $\mathrm{CO}_{2}$ to produce formic acid $(\mathrm{HCOOH})$ and $\mathrm{O}_{2}$. Formic acid is the primary fuel. Formic acid has been classified as a liquid fuel as hydrogen is only released for the liquid formic acid as require.

\section{Viability of the proposed projects}

United Kingdom had played a major role in advocating for reduction of $\mathrm{CO}_{2}$ emission and has strongly supported the deployment of CCS as part of a broader strategy to combat climate change/green house effects. Also the emerging uses of $\mathrm{CO}_{2}$ world wide can be harnessed in Nigeria to generate about N10 billion Naira (yearly).

The market price of $\mathrm{CO}_{2}$ is in the range of $\$ 20-46$ per tonne. The combined system of materials, Equipments and manpower can produce 20 to 50 tonnes of Co2 per day which will cost \$ 920 per day, averaging $\$ 335,800$ (U.S. dollars) per annum. Other benefits accrue from blast furnace and charcoal Briquetting processes. 


\subsection{Materials and Equipment needed}

1. 4 pcs Laptops (500G) with internet facilities

N500,000

2. 1 Pcs Printer

120,000

3. photocopier/Scanner

450,000

4. Paper work \& Stationeries

100,000

5. Officer equipment

100,000

6. Blast furnace construction

7.0 million

7. Generator 25KVA

4.5 million

8. Change over for the blast furnace for $\mathrm{CO} 2$ generation

2.0 million

9. 1 plot of land

10. Centrifuge compressor to compress $\mathrm{Co} 2$

3.5 million

11. Books/internet bills

3.5 million

12. Construction of storage tank

300,000

13. Oversea training at University of Nottingham U.K for two key personnel

3.2 million

Total Cost

\subsection{Manpower requirement}

\begin{tabular}{|c|l|c|}
\hline S/N & \multicolumn{1}{|c|}{ Staff } & Salary per year \\
\hline 1 & 1 Civil Engineer & 1.5 million \\
\hline 2 & 1 Mechanical Engineer & 1.5 million \\
\hline 3 & 1 Chemist & 1.5 million \\
\hline 4 & 1 confidential Secretary & 1.0 million \\
\hline 5 & 5 Unskilled Labour & 500,000 \\
\hline \multicolumn{2}{|c|}{ Total cost } & $\mathbf{6 , 0 0 0 , 0 0 0}$ \\
\hline
\end{tabular}

Total project Cost of Manpower Requirement is $\quad=\quad$ N36.27M

\section{Risk Assessment}

Numerical simulations on existing storage projects conclude that very long retention times are to be expected with geological storage. A study on the sleipner field concludes that no $\mathrm{CO}_{2}$ would migrate into the North sea for 100000 years, and that even after a million years, the annual rate of release would be only one millionth of the stored $\mathrm{CO}_{2}$ (lindeberg and Bergbom, 2003). A study of the Forties Oilfield on the effects of uncertainties of in paramteters such as flow velocity in the aquifer and capillary entry pressure into the caprock, showed that less than $0,2 \%$ of the Co2 would escape into the overlying layers within 1000years, and even in the worst case, the maximum vertical distance moved by any of the $\mathrm{CO}_{2}$ was less than halway to the seabed within this period (cawley et al,2005). Similarly, one study of the Weyburn storage site showed that within 5000 years there was $95 \%$ probability that less than $1 \%$ of the stored $\mathrm{Co}_{2}$ would be released into the bisosphere (Walton et al., 2005) and another study of the same site found nor release to the atmosphere 5000 years at all (Zhou et al, 2005).

\section{Conclusion and Recommendations}

Carbon (iv) oxide or $\mathrm{CO}_{2}$ capture was initiated by the Researchers to reduce the climatic problems associated with the accumulation of carbon (ii) oxide (carbon monoxide) in the atmosphere. This gives rise to a lot of people fainting on suffocation (or even death), ozone layer depletion and various green house effects.

These problems remained over the years in the country. However, carbon (iv) oxide $\left(\mathrm{CO}_{2}\right)$ 's potential and uses discussed in this paper will go a long way in development of oil and gas 
industries and cement production and steel producers which are the major revenue generation of the country and if harnessed properly in Nigeria will create Jobs for unemployed youths, aid oil and Gas industries and add value to the social well being of the populace.

Lastly, the Federal Government of Nigeria while trying to invest $\$ 4$ billion dollars to finance a coal - fired power plant in Benue state come 2013 should utilize this technology to convert synthesis gas and $\mathrm{CO}_{2}$ capture to methanol (blue fuel) which will become basis for a clean energy economy that actually reduce global warming by turning a potential green house gas, $\mathrm{CO}_{2}$ into a global warming solution (fuel), etc.

\section{References}

Azar et al (2001), Targets for stabilization of atmospheric $\mathrm{Co}_{2}$, Science 776,. Pp 1818-1819

Ekstrom et al (1997), Technologies and costs in Sweden for capture and storage of $\mathrm{CO}_{2}$ from combination of fossil fuel for production of power and Heat, Stockholm, Sweden

IPCC (2005), Carbon dioxide capture and storage New York. NY Cambridge University press

J ohnansson (1996), Capturing $\mathrm{CO}_{2}$. IEA Greenhouse Gas R and D program me, Harvard University USA.

Keith and Rhode (2002), "bury, burn or both . A two for one deal on biomass carbon and energy", clim change 54 (3), 375-377

Mollersten and Yan (2001), Economic evaluation of biomass based energy systems with $\mathrm{CO}_{2}$ capture and sequestration in kraft pulp mills, world resource, Rev I3 (4), 509-525

Obersteiner et cl (2001), "Managing Climatic risk" Science 294 (5543), pp 786 - 787.

Parson and Keith (1998), "Fossil fuels without $\mathrm{CO}_{2}$ emissions. Progress, prospects and policy implications", Science 282, pp 1053 - 1054

Williams (2001), "Towards zero emission from coal in china ," presented at U.S.A, china clean Energy forum Beijing(31 August) 